\title{
An Empirical Analysis and Countermeasure Research on the Effect of Logistics Industry on Economic Growth in China
}

\author{
Xueping Deng ${ }^{a}$, Jingwen Guo ${ }^{b}$ \\ School of Economics and Management, Chongqing University of Posts and Telecommunications, \\ Chongqing, 400065, China \\ aDengxp@cqupt.edu.com, b1290135159@qq.com
}

\begin{abstract}
In order to study the logistics industry's effect on promoting economic growth, firstly this paper demonstrates the research of the interaction between the two on the basis of the data of GDP and the total social logistics in the period from 1991 to 2013, in the method of Granger-causality test. The result illustrates that there is mutual Granger-causality between the logistics and economic growth. Then, the paper empirically analyzes the contribution of logistics industry to the development of national economy through the GDP for social logistics demand coefficient (LDC), the logistics industry to GDP contribution rate (LCR) and pulling coefficient (LPC). The results present that the relationship between logistics industry and economic growth shows that more obvious is the promoting influence of economic on the logistics industry than the other way around. Finally, according to analysis of the cause about the coefficient changes, some strategic suggestions are provided for development of modern logistics industry to economic growth effectively.
\end{abstract}

Keywords: Logistics Industry; Economic Growth; Empirical Analysis; Countermeasures.

\section{Introduction}

Since the 1980s, influenced by the reform and opening policies, Chinese economy has achieved an unprecedented pace of development. According to statistics from National Bureau of Statistics of China (NBS), the GDP increased from 2.18 trillion RMB to 56.88 trillion RMB during 1991 to 2013, annual growth rate actually was 16\%; Meanwhile, according to the statistics of International Monetary Fund (IMF), the contribution rate of China for globally economic growth in 2014 would reach $27.8 \%$, while in the same year the contribution rate of U.S. for globally economic growth would be $15.3 \%$. China had a large effect on stimulating globally economic growth. The rapid development of China's logistics industry was driven by the good circumstances of economy and the rapid growth of market demand. The logistics industry was 3.9 trillion RMB in 2013, which accounts for $6.8 \%$ of GDP. Generally speaking, with the limit of the dual economic structure, the promoting effect of the logistics industry on economic growth is at a lower level.

Previous studies of foreign scholars had emphasized that the logistics industry is of great significance for other industries in the country [1]. In 1980, Angela examined the importance of the logistics industry to the UK economy development [2]. Aoyama pointed out the significance of logistics industry in the modern industrialization from the perspective of Economic Geography [3]. Many of researches in China has proven the mutual role between the logistics industry and the regional economic growth. For example, Li Quanxi used the panel data from 2003 to 2008 of 31 provinces in China to analyze the relationship between regional logistics capability and regional economic development [4]; Sun Haojie considered that the development of modern logistics could promote the optimization and upgrading of the third industry, as well as the adjustment of industry structure[5]; Jin Fangfang worked on the empirical analysis about the impact of the logistics industry in different periods and regions of Chinese economic growth[6]; Wan Hongyan probed into the process of interaction between the logistics industry and economic growth[7]. In 2014, the State Council issued "Logistics industry development and long-term planning (2014-2020)", which emphasizes that logistics industry is the basic and strategic industry of the national economy. What's more, it indicates explicitly that logistics industry can promote the industrial structure adjustment, help fuel the economic growth and enhance the national economic competitiveness. Thus, 
accelerating the development of logistics industry is a key to promote our nation's economic growth, and conducting the research of function and position of logistics industry in economic growth has positive and realistic significance for the stable and sustainable development to drive economic growth.

\section{THEORETICAL MODEL}

In order to analyze the impact of the modern logistics industry on China's economic growth and contribution, first of all, proving the existence of a causal relationship between the two is necessary, because only under the premise can be carried out the research of the degree of relevant contribution. Therefore, firstly test the causal relationship between modern logistics industry and the domestic economic growth. Secondly, select the appropriate econometrics methods and determine variables. Then, through quantitative calculation, get the role and contribution of the extent of logistics industry on economic growth.

\subsection{Grander-Causality Test}

It is universally acknowledged that at present, most of scholars commonly used causality test method proposed by Clive W. J. Granger in 1969 to analyze the mutual relationship between variables. Granger causality test is a model which can determine whether the information of prophase variable will affect the information of another variable in the following, if this effect exists, it means that the two variables have Granger causality. The basic theory of the Granger-causality test is the following: For an observed model:

$$
Y_{t}=\alpha_{0}+\sum_{i-1}^{m} \alpha_{i} Y_{t-i}+\sum_{j-1}^{n} \beta_{j} X_{t-j}+\mu_{t}
$$

( $\alpha, \beta$ are the coefficient term (among them, $\alpha_{0}$ is constant), $\mu_{t}$ is a mean zero random error.)

$H_{0}$ : $\beta_{j}=0(j=1,2, \ldots, n), \mathrm{X}$ does not Granger Cause Y.

$H_{1}: \exists j$ at least. ST: $\beta_{j} \neq 0, \mathrm{X}$ can Granger Cause $\mathrm{Y}$.

Then model (1) can be turned into:

$$
Y_{t}=\alpha_{0}+\sum_{i=1}^{m} \alpha_{i} Y_{t-i}+\mu_{t}
$$

Thus the residual sum of squares of model (1) is $R S S_{1}$, the residual sum of squares of model(2) is $R S S_{2}$, and calculate statistics $S_{1}$ :

$$
S_{1}=\frac{\left(R S S_{2}-R S S_{1}\right) / n}{R S S_{1} /(T-m-n-1)} \sim F(n, T-m-n-1)
$$

$S_{1}$ obeys the F distribution whose degrees of freedom is $\mathrm{n}$; $\mathrm{T}$ represents the number of samples; $\mathrm{m}$ represents Y's lags while $\mathrm{n}$ represents X's lags. If $S_{1}$ is bigger than the critical value of $\mathrm{F}$, then we reject $H_{0}$. Otherwise, we accept $H_{0}: \mathrm{X}$ does not have Granger Cause with $\mathrm{Y}$.

\subsection{Social Logistics Demand Coefficient (LDC)}

LDC refers to the total amount of logistics required by per unit of GDP, which means that how much unit of the total logistics support output per unit of GDP. LDC is the indicator to reflect the dependence of GDP on the logistics industry, which is calculated as:

$D_{t}^{i}=\frac{A_{t}^{i}}{G D P}$

$D_{t}^{i}$ is the ratio of the logistics demand to the output of GDP

$A_{t}^{i}$ is the Total Logistics.

\subsection{The Industrial Contribution Rate (ICR)}

ICR is a significant indicator to measure the contribution of the industry. It can reflect the degree of influence of logistics industry on economic growth, which measures the contribution of the logistics 
industry to the national economy development. ICR is the ratio of the logistics industry increment to GDP growth increment, which is calculated as:

$C_{t}^{i}=\frac{Y_{t}^{i}-Y_{t-1}^{i}}{Y_{t}-Y_{t-1}}$

$C_{t}^{i}$ is the ratio of the contribution of the logistics industry to the national economy development; $Y_{t}^{i}$ is the logistics industry's added value in the current year, $Y_{t-1}^{i}$ is the logistics industry's added value in the previous year;

$Y_{t}$ is the added value of GDP in the current year, $Y_{t-1}$ is the added value of GDP in the previous year.

\subsection{The Industrial Pulling Coefficient (IPC)}

It reflects the degree of contribution of logistics industry on economic growth. IPR is the ratio of the product of ICR and GDP growth rates, which is calculated as:

$P_{t}^{i}=C_{t}^{i} * r_{t}$

$P_{t}^{i}$ is ratio of the logistics industry pulling forward the national economy development;

$r_{t}$ is the GDP growth rate in the current year.

\section{EMPIRICAL ANALYSIS}

\subsection{Grander Causality Test of Logistics Industry and Economic growth}

Table 1. Statistics of the Total Social Logistics from 1991 to 2013

\begin{tabular}{cccccccc}
\hline Year & $\begin{array}{c}\text { Industrial } \\
\text { products(X1) }\end{array}$ & $\begin{array}{c}\text { Agriculture } \\
\text { products } \\
(\mathrm{X} 2)\end{array}$ & $\begin{array}{c}\text { Imported } \\
\text { goods } \\
(\mathrm{X} 3)\end{array}$ & $\begin{array}{c}\text { Renewable } \\
\text { resources } \\
(\mathrm{X} 4)\end{array}$ & $\begin{array}{c}\text { Units and } \\
\text { residents } \\
(\mathrm{X} 5)\end{array}$ & $\begin{array}{c}\text { Total } \\
\text { logistics } \\
(\mathrm{X})\end{array}$ & $\begin{array}{c}\text { GDP } \\
(\mathrm{Y})\end{array}$ \\
\hline 1991 & 2.3418 & 0.3252 & 0.3395 & 0.0128 & 0.0027 & 3.0221 & 2.17815 \\
\hline 1992 & 3.1121 & 0.3335 & 0.4444 & 0.0155 & 0.0033 & 3.9088 & 2.69235 \\
\hline 1993 & 4.378 & 0.4281 & 0.599 & 0.0222 & 0.0042 & 5.4315 & 3.53339 \\
\hline 1994 & 6.2571 & 0.6104 & 0.9964 & 0.0548 & 0.005 & 7.9237 & 4.81979 \\
\hline 1995 & 8.2584 & 0.7951 & 1.1029 & 0.0352 & 0.0059 & 10.1975 & 6.07937 \\
\hline 1996 & 8.973 & 0.8618 & 1.1523 & 0.0347 & 0.0069 & 11.0288 & 7.11766 \\
\hline 1997 & 10.2501 & 0.8996 & 1.1817 & 0.0274 & 0.0078 & 12.3665 & 7.8973 \\
\hline 1998 & 10.7688 & 0.916 & 1.1626 & 0.0172 & 0.0086 & 12.8732 & 8.44023 \\
\hline 1999 & 11.5827 & 0.9138 & 1.3736 & 0.0155 & 0.0098 & 13.8954 & 8.96771 \\
\hline 2000 & 14.2 & 0.9634 & 1.866 & 0.015 & 0.0116 & 17.0561 & 9.92146 \\
\hline 2001 & 16.3739 & 1.0291 & 2.0159 & 0.0199 & 0.0126 & 19.4513 & 10.96552 \\
\hline 2002 & 19.6799 & 1.0986 & 2.4431 & 0.0235 & 0.0132 & 23.2583 & 12.03327 \\
\hline 2003 & 24.957 & 1.1261 & 3.4193 & 0.0278 & 0.0187 & 29.5488 & 13.58228 \\
\hline 2004 & 32.4876 & 1.197 & 4.6467 & 0.0325 & 0.019 & 38.3829 & 15.98783 \\
\hline 2005 & 41.3161 & 1.2748 & 5.4093 & 0.0376 & 0.0205 & 48.0583 & 18.49374 \\
\hline 2006 & 51.6864 & 1.3546 & 6.3267 & 0.2059 & 0.024 & 59.5976 & 21.63144 \\
\hline 2007 & 66.0878 & 1.5849 & 7.2627 & 0.2436 & 0.0493 & 75.2283 & 26.58103 \\
\hline 2008 & 79.8622 & 1.8638 & 7.8603 & 0.2529 & 0.0562 & 89.8953 & 31.40454 \\
\hline 2009 & 87.4058 & 1.9439 & 6.857 & 0.284 & 0.1632 & 96.6538 & 34.0903 \\
\hline 2010 & 113.1031 & 2.2355 & 9.4305 & 0.4464 & 0.1975 & 125.413 & 40.15128 \\
\hline 2011 & 143.6 & 2.6 & 11.2 & 0.5 & 0.2 & 158.4 & 468562.4 \\
\hline 2012 & 162 & 2.9 & 11.5 & 0.7 & 0.2 & 177.3 & 519470.1 \\
\hline 2013 & 181.5 & 3.1 & 12.1 & 0.8 & 0.3 & 197.8 & 568845.2 \\
\hline & & & & & & & \\
\hline & & & & & & & \\
\hline
\end{tabular}


According to the above model, we based on the data of GDP (Y) and the related indexes of logistics industry including Total social logistics (X), Total industrial logistics (X1), Total agriculture logistics (X2), Total imports of goods logistics (X3), Total amount of renewable resources in logistics (X4), Total logistics activities of units and residents (X5) from 1991 to 2013. Furthermore, we analyzed the relationship between these variables by using econometrics methods such as Granger-causality Test. Considering that the logistics data statistics are measured with long lags, in order to ensure the robustness and reliability of the test results, we tested the causal relationship between these variables with four lags by using Granger-causality Test. The test results are shown in Table 2 indicate: Except Y dose not have Granger Cause with X2, X3, X4 in lags 1, 2. And Y dose not have Granger Cause with X3, X4 dose not have Granger Cause with Y in lags 3. In other lags of X, X1, $\mathrm{X} 2, \mathrm{X} 3, \mathrm{X} 4, \mathrm{X} 5$ and Y have mutual Grander- causality. Thus it can be seen, during 1991 to 2013, the logistics industry in China took positive role in promoting economic growth, at the same time, economic growth provided development of logistics industry with a favorable environment, and it also drives the development of the logistics industry up.

\subsection{The original data of this research are from China Statistics Annual and China Logistics Yearbook.}

Table 2. Results of the Logistics Industry and GDP with Grander-Causality Test

\begin{tabular}{|c|c|c|c|c|}
\hline Null Hypothesis: & Lags: 1 & Lags:2 & Lags:3 & Lags:4 \\
\hline $\mathrm{X}$ does not Granger Cause $\mathrm{Y}$ & $10.3036 * * *$ & $11.7619 * * *$ & $77.9573 * * *$ & $48.6188 * * *$ \\
\hline $\mathrm{X} 1$ does not Granger Cause Y & $10.6636 * * *$ & $10.8509 * * *$ & $81.1297 * * *$ & $61.6196 * * *$ \\
\hline $\mathrm{X} 2$ does not Granger Cause $\mathrm{Y}$ & $7.10029 * *$ & $4.42131 * *$ & 2.05956 & $9.45788 * * *$ \\
\hline X3 does not Granger Cause Y & $6.3424 * *$ & $9.00774 * * *$ & $36.1665 * * *$ & $30.0249 * * *$ \\
\hline $\mathrm{X} 4$ does not Granger Cause $\mathrm{Y}$ & $14.8012 * * *$ & $8.13877 * * *$ & 1.82914 & $7.63788 * * *$ \\
\hline X5 does not Granger Cause Y & $22.3 * * *$ & $82.2641 * * *$ & $99.6561 * * *$ & $236.579 * * *$ \\
\hline Y does not Granger Cause $\mathrm{X}$ & $18.7834 * * *$ & $7.71396 * * *$ & $1.72047 *$ & $2.74373 *$ \\
\hline Y does not Granger Cause X1 & $23.5973 * * *$ & $9.50535 * * *$ & $2.39118 *$ & $3.34373^{*}$ \\
\hline $\mathrm{Y}$ does not Granger Cause X2 & 0.5514 & 0.76958 & $14.1919 * * *$ & $11.1292 * * *$ \\
\hline Y does not Granger Cause X3 & 2.43015 & 1.17885 & 1.42822 & $2.82992 *$ \\
\hline $\mathrm{Y}$ does not Granger Cause X4 & 0.7254 & 1.26161 & $2.79267^{*}$ & $4.03722^{* *}$ \\
\hline Y does not Granger Cause X5 & 0.6399 & $3.96761 * *$ & $5.67015 * *$ & $12.2677 * * *$ \\
\hline
\end{tabular}

\section{The Variation Analysis on LDC, ICR \&IPC}

\subsection{Variation Analysis of the logistics demand coefficient from 1991 to 2013}

According to the above analysis, we selected the related indexes of logistics industry including Total social logistics, Total industrial logistics, Total agriculture logistics, Total imports of goods logistics, Total amount of renewable resources in logistics, Total logistics activities of units and residents, and using GDP as described Chinese economic development indicator. Through the demand coefficient formula, we calculate the demand coefficient of logistics in China from 1991 to 2013.

Table 1 shows that, in recent years, the Total social logistics and the GDP has been constantly growing. Table 3 reflects the demand Coefficient of GDP to Logistics. It can be seen with the economic development, and the degree of dependence of GDP on the logistics increasing significantly. In 1991, Per unit of GDP output needs a total of 1.38 units of social logistics to support. By 2013, per unit of GDP output needs a total of 3.48 units of social logistics to support. In the period from 1991 to 2013, GDP for social logistics demand coefficient basically maintain a growth trend, in addition to 1996 and 1998 the coefficient decreased, but all other years it remained in an upward trend. From the point of classification, demand coefficient of Total industrial logistics is maximum, while the demand coefficient of the units and residents of goods logistics is minimal. Demand coefficient on Total 
industrial logistics keeps increasing year by year, except for the 1996 and 1998; Basically, demand coefficient on the Total agriculture logistics is a downward trend, except for the 1994 and 1995; Due to the rapid development of e-commerce such as online shopping promotion, Demand coefficient of the units and residents of logistics began to improve significantly from 2009; Demand coefficient on Total imported goods logistics and Total renewable resources logistics did not change obviously. We can find that China's GDP of logistics dependence is increasing year by year. Among them, the biggest dependence is industrial products, agricultural products and other four types of industries dependence are relatively small.

Table 3.the Demand Coefficient of GDP to Logistics from 1991 to 2013

\begin{tabular}{|c|c|c|c|c|c|c|}
\hline Year & Industrial & Agriculture & Imported & Renewable & Units and & Total \\
\hline 1991 & 1.0751 & 0.1493 & 0.1559 & 0.0059 & 0.0012 & 1.3875 \\
\hline 1992 & 1.1559 & 0.1239 & 0.1651 & 0.0058 & 0.0012 & 1.4518 \\
\hline 1993 & 1.2390 & 0.1212 & 0.1695 & 0.0063 & 0.0012 & 1.5372 \\
\hline 1994 & 1.2982 & 0.1266 & 0.2067 & 0.0114 & 0.0010 & 1.6440 \\
\hline 1995 & 1.3584 & 0.1308 & 0.1814 & 0.0058 & 0.0010 & 1.6774 \\
\hline 1996 & 1.2607 & 0.1211 & 0.1619 & 0.0049 & 0.0010 & 1.5495 \\
\hline 1997 & 1.2979 & 0.1139 & 0.1496 & 0.0035 & 0.0010 & 1.5659 \\
\hline 1998 & 1.2759 & 0.1085 & 0.1377 & 0.0020 & 0.0010 & 1.5252 \\
\hline 1999 & 1.2916 & 0.1019 & 0.1532 & 0.0017 & 0.0011 & 1.5495 \\
\hline 2000 & 1.4312 & 0.0971 & 0.1881 & 0.0015 & 0.0012 & 1.7191 \\
\hline 2001 & 1.4932 & 0.0938 & 0.1838 & 0.0018 & 0.0011 & 1.7739 \\
\hline 2002 & 1.6355 & 0.0913 & 0.2030 & 0.0020 & 0.0011 & 1.9328 \\
\hline 2003 & 1.8375 & 0.0829 & 0.2517 & 0.0020 & 0.0014 & 2.1755 \\
\hline 2004 & 2.0320 & 0.0749 & 0.2906 & 0.0020 & 0.0012 & 2.4008 \\
\hline 2005 & 2.2341 & 0.0689 & 0.2925 & 0.0020 & 0.0011 & 2.5986 \\
\hline 2006 & 2.3894 & 0.0626 & 0.2925 & 0.0095 & 0.0011 & 2.7551 \\
\hline 2007 & 2.4863 & 0.0596 & 0.2732 & 0.0092 & 0.0019 & 2.8301 \\
\hline 2008 & 2.5430 & 0.0593 & 0.2503 & 0.0081 & 0.0018 & 2.8625 \\
\hline 2009 & 2.5639 & 0.057 & 0.2011 & 0.0083 & 0.0048 & 2.8351 \\
\hline 2010 & 2.8169 & 0.0557 & 0.2349 & 0.0111 & 0.0049 & 3.1235 \\
\hline 2011 & 3.0618 & 0.0554 & 0.2388 & 0.0107 & 0.0043 & 3.371 \\
\hline 2012 & 3.1214 & 0.0559 & 0.2216 & 0.0135 & 0.0039 & 3.4163 \\
\hline 2013 & 3.1898 & 0.0545 & 0.2127 & 0.0141 & 0.0053 & 3.4764 \\
\hline
\end{tabular}

4.2 Variation Analysis about the Logistics Contribution rate and the Logistics Pulling coefficient

According to GDP and the logistics scale increments from 1991 to 2013, we calculated the Logistics Contributions rate and the Logistics Pulling coefficient on the domestic economy growth. These indicators are used to reflect the contributions of modern logistics industry on the national economy, to make sure that modern logistics has become an important industry in our national economy. The ability of logistics is used to reflect directly the development of logistics industry, and the growth of logistics industry is a core indicator to reflect the development of logistics industry.

We can see clearly from Table 4 that, over the years, the logistics industry accounting for the proportion in the national economy has been maintained around $6 \%$, and the average contribution rate of logistics industry to GDP growth was $6.81 \%$. Result simply demonstrates that modern logistics industry is an indispensable part of the national economy and it plays an extremely crucial role in the development of the national economy. Furthermore, by analyzing the annual pulling coefficient of logistics, interaction between logistics industry and national economy patterns can be found. Although the logistics industry has obtained rapid development in recent years, the pulling coefficient of the logistics was at $0.7 \%$ on average, and this ratio just exceeded $1 \%$ in 2009 . Relatively speaking, the speed of logistics development is slightly slower than the speed of national economic development. The relationship between the two manifests economic development boots logistics 
industry. However, it is not obvious that logistics promote development of economy. On the development trend, there are no significant growth trend for the contribution rate and the pulling coefficient. In other words, they remained stable. Compared with the developed countries, the current level of China has a certain gap with them. The analysis infers that the role of the modern logistics industry has not been fully exploited, for economic growth the contribution has not fully reflected. Therefore, the country needs to increase investment in the logistics industry, optimize the structure of the logistics industry, thus making the modern logistics industry in national economic development can play a greater role.

Table 4. Contribution of Logistics Industry to the Development of National Economy

\begin{tabular}{c|c|c|c|c|c|c|c|c}
\hline & \multicolumn{3}{|c|}{ GDP } & \multicolumn{2}{c|}{ Logistics } & & \\
\cline { 2 - 6 } Year & $\begin{array}{c}\text { GDP } \\
\text { increments } \\
\text { (billion) }\end{array}$ & $\begin{array}{c}\text { Amount of } \\
\text { Growth } \\
\text { (billion) }\end{array}$ & $\begin{array}{c}\text { GDP } \\
\text { growth } \\
\text { rate } \\
\%\end{array}$ & $\begin{array}{c}\text { Logistics } \\
\text { increments } \\
\text { (billion) }\end{array}$ & $\begin{array}{c}\text { the } \\
\text { Amount } \\
\text { of Growth } \\
\text { (billion) }\end{array}$ & $\begin{array}{c}\text { Logistics } \\
\text { increments } \\
\text { accounting\% }\end{array}$ & $\begin{array}{c}\text { LCR } \\
\%\end{array}$ & LPC\% \\
\hline 1991 & 21781.50 & 3113.70 & 9.18 & 1851 & - & 6.5 & - & - \\
\hline 1992 & 26923.50 & 5142.00 & 14.24 & 2174 & 323 & 6.2 & 6.28 & 0.89 \\
\hline 1993 & 35333.90 & 8410.40 & 13.96 & 2906 & 732 & 6.1 & 8.7 & 1.22 \\
\hline 1994 & 48197.90 & 12864.00 & 13.08 & 3654 & 748 & 5.8 & 5.81 & 0.77 \\
\hline 1995 & 60793.70 & 12595.80 & 10.92 & 4265 & 611 & 5.3 & 4.85 & 0.53 \\
\hline 1996 & 71176.60 & 10382.90 & 10.01 & 4996 & 731 & 5.3 & 7.04 & 0.7 \\
\hline 1997 & 78973.00 & 7796.40 & 9.30 & 5398 & 402 & 5.2 & 5.16 & 0.48 \\
\hline 1998 & 84402.30 & 5429.30 & 7.83 & 5858 & 460 & 5.5 & 8.47 & 0.66 \\
\hline 1999 & 89677.10 & 5274.80 & 7.62 & 6416 & 558 & 5.7 & 10.58 & 0.81 \\
\hline 2000 & 99214.60 & 9537.50 & 8.43 & 6887 & 471 & 6.2 & 4.94 & 0.42 \\
\hline 2001 & 109655.20 & 10440.60 & 8.30 & 7429 & 542 & 6.2 & 5.19 & 0.43 \\
\hline 2002 & 120332.70 & 10677.50 & 9.08 & 7927 & 498 & 6.2 & 4.66 & 0.42 \\
\hline 2003 & 135822.80 & 15490.10 & 10.03 & 9112 & 1185 & 5.8 & 7.65 & 0.77 \\
\hline 2004 & 159878.30 & 24055.50 & 10.09 & 10776 & 1664 & 5.8 & 6.92 & 0.7 \\
\hline 2005 & 184937.37 & 25059.07 & 11.31 & 12271 & 1495 & 5.7 & 5.97 & 0.67 \\
\hline 2006 & 216314.43 & 31377.06 & 12.68 & 14120 & 1849 & 5.6 & 5.89 & 0.75 \\
\hline 2007 & 265810.31 & 49495.88 & 14.16 & 16981 & 2861 & 5.4 & 5.78 & 0.82 \\
\hline 2008 & 314045.43 & 48235.12 & 9.63 & 19965 & 2984 & 5.2 & 6.19 & 0.6 \\
\hline 2009 & 340902.80 & 26857.37 & 9.21 & 23078 & 3113 & 4.8 & 11.59 & 1.07 \\
\hline 2010 & 401512.80 & 60610.00 & 10.45 & 27310 & 4232 & 4.6 & 6.98 & 0.73 \\
\hline 2011 & 473104.00 & 71591.20 & 9.30 & 32000 & 4690 & 4.5 & 6.55 & 0.61 \\
\hline 2012 & 519470.10 & 46366.10 & 7.65 & 35000 & 3000 & 4.4 & 6.47 & 0.5 \\
\hline 2013 & 568845.20 & 49375.10 & 7.67 & 39000 & 4000 & 4.4 & 8.1 & 0.62 \\
\hline
\end{tabular}

\section{Results and discussion}

\subsection{The Changes of the Logistics Demand Coefficient.}

On one hand, owing to the implementation of the policy of reform and opening up, China's economy has made rapid development. Especially after joining the WTO in 2001, characterized with manufacturing industry of the "world processing center" transferring quickly to China. The industrial production capacity boosts greatly, "made in China" products continuously flow to every corner of the world. Meanwhile, thanks for the increasing ability of the domestic demand contributes to the rapid industrial production development. Thus, throughout this period, GDP on the logistics demand coefficient of industrial products and imported goods always kept rising trend, and especially 
industrial goods logistics demand has remained at a high level. In 2011, it exceeded 3.0618, far higher than other industries logistics volume.

On the other hand, under the background of industry development, the awareness of stressing industry and overlooking agriculture is widely existed among a large number of rural residents. Young adults generally work as migrant worker outside hometown, it leads to rural land idle. In the meantime, a large number of cultivated lands were destroyed due to the rapid development of urbanization. As a result, the demand coefficient of GDP was in a slipping tendency although the total logistics of agricultural products increased in total. In addition, The use of renewable resources in China did not receive enough attention, and government also did not take strong, effective measures and policies to guide the development of renewable resources. Consequently, the amount of renewable resources logistics was at a relatively low development level.

\subsection{The Logistics Contribution rate and the Logistics Pulling coefficient variation}

From the above analysis results, the following conclusions can be made: The first and foremost, the development of logistics industry in China has positive driving effect on economic growth. Nationally, every 100 million RMB increase of added value of the logistics industry can make an increase of 681 million RMB GDP. Modern logistics plays a paramount role in promoting national economic growth and industrial structure transformation. Consequently it is urgently necessary to promote national economic growth through vigorous development the logistics industry. It also corresponds to the strategy which was issued by the State Council "Logistics industry development and long-term planning (2014-2020)" in 2014. The strategy emphasizes that logistics industry explicitly indicates that logistics industry can help fuel the economic growth and enhance the national economic competitiveness.

There is one more point we should touch on, that from the perspective of the contribution of logistics industry to economic growth, the contribution rates of logistics have been at a lower level. In recent years, despite the fast development of China's logistics industry, the industry has still been facing the separation of departments, regional segmentation management system constraints, the lack of specialized logistics service needs, insufficient supply of logistics personnel, specialized logistics service supply constraints and others [8-10]. Compared with the developed countries, no matter in industrial scale, technological level, logistics informatisation and standardization Chinese logistics industry has been in a relatively backward level. From the concrete numerical point of view, from 1991 to 2013, the contribution rate of the logistics industry to economic growth was about $6.81 \%$ annually, and the rate was far below the average level in developed countries over $10 \%$; Meanwhile, the pulling rate of the logistics industry to economic growth was $0.7 \%$. This manifests that the overall level of China's logistics industry was still low. It is necessary to promote the smooth development of the logistics industry upgrading and industrial transformation for our country. We can implement the following measures: increase investment in the construction of logistics infrastructure and rational layout of the logistics industry; Prevent regional fragmentation; Prompt the investment shift of logistics industry from extensive to intensive; Upgrade logistics technology investment and application efficiency; Improve logistics informatization and standardization level. Further, it is also crucial to promote the development of the national economy and promote the adjustment of industrial structure in China.

\section{Countermeasure analysis}

Logistics industry is supporting system of national economic development, largely affecting the inclusive development of economic society. In 2013 the value of China's GDP increased 56.9 trillion. The contribution of logistics industry to the economy growth accounted for $8.1 \%$. In contrast, it kept the rate of $15 \%$ in US. For better development of the logistics industry and achieving the promotion of economic, following aspects should be proceed. 


\subsection{Strengthen the Logistics Infrastructure Construction}

The first is to accelerate the standardization of logistics. Starting from logistics information standards, service standards and management standards, referring to general international standards, national standards related logistics should be formulated;

The second is to perfect urban and rural distribution network. China has realized comparatively systematic transportation system backbone of sea, air and land. But policy should also be carried out to improve the multi-level urban and rural distribution network, thus forming a perfect urban and rural distribution system as a whole;

The third is to promote the application of information technology logistics. Promote the upgrading of the logistics enterprise information system; Improve enterprise logistics information management level; Vigorously promote the radio frequency identification (RFID), electronic data interchange (EDI), automated sorting and other logistics application of new technologies.

\subsection{Foster the Growth of the Logistics Market}

One is to guide the release of logistics demand, and promote internal logistics socialization. For the enterprises of production and commercial circulation, encourage them to transform the internal business processes, and promote integration and outsourcing of procurement, production and marketing and other aspects of logistics; second is to guide, encourage manufacturing, logistics and commercial circulation enterprises to establish the industry supply chain alliance; Promote strategic cooperation. The third is to encourage common development of logistics companies, manufacturing and business enterprises; Expand domestic and foreign markets; Focus on promoting IT, Auto, equipment manufacturing, chemicals, materials and other industries ,combined development with logistics industry.

\subsection{Promote the Optimization of the Logistics Industry}

The first is to strengthen regional and international cooperation in logistics, and actively establish strategic cooperation mechanisms in regional logistics areas; Develop policy coordination and technical cooperation of logistics business; Promote the opening of the logistics industry and investment, and improve the degree of logistics internationalization and regionalization. The second is to support the growth of a number of logistics enterprises backbone which are potential and have already obtained a certain foundation; Introduce a number of advanced logistics enterprises which obtain influence on international, introducing and absorbing experience and management practices of advanced foreign logistics companies, and promoting the development of local logistics enterprises; Foster a number of social, professional, personalized third-party logistics services business.

\subsection{Develop Multi-level Logistics Personnel}

The first is to establish a sound education and vocational training system. Strengthen the construction system of logistics specialty in higher institutions; Improve the vocational training centers and other institutions run with social resources, train various of logistics professionals; The second is to strengthen exchanges and cooperation with foreign logistics personnel, and promote the training and growth of our logistics personnel.

\section{Acknowledgments}

This work was supported by the Soft Subject Communication Research of the Ministry of Industry and Information Technology (2014-R-4), the Science and Technology Project of Chongqing Municipality Education Commission (NO: KJ1305260), the Humanities and Social Science Project of Chongqing Municipality Education Commission (NO: 111SKF19).

\section{References}

[1] Danuta Kisperka-Moron. "Logistics change during the transition period in the Polish economy," International Journal of Production Economies, 1994, 35(1-3): 23-28

[2] Angela Childerley, "The Importance of Logistics in the UK Economy," The Importance of Logistics in the UK Economy, 1980,10(4):185-192. 
[3] Yuko Aoyama, Samuel Ratick, and Guido Schwarz, "Organizational Dynamics of the U.S. Logistics Industry: An Economic Geography Perspective," The Professional Geographer, 2006,58(3): 327-340.

[4] LI Quexi, JIN Fenghua, and SUN Panshi, “Analysis of Canonical Correlation between Regional Logistics Capability and Regional Economic Development—Based on National Panel Data," Soft Science, 2010,12:75-79.

[5] SUN Hao-jie, WU Qun-qi, "An Empirical Study on the Impact of the Logistics Industry to Economic Structure ," On Economic Problems, 2011, 06:27-31.

[6] Jin Fang-fang, "The Logistics Industry Development: An Empirical Study of Driving Effect on Economic Growth," Inquiry to Economic Issues, 2012,03:135-140.

[7] WAN Hongyan, WANG Zhidong. "An Empirical Research on the Relationship between Logistics and Economic Growth in China," Journal of Central South University (Social Science), 2014, 02:7-13.

[8] Li Wen shun, "The association analysis between the logistics growth and the GDP growth in 1952-1992 in China," China Soft Science, Vol. 12, 2004, pp. 45-49.

[9] Yan Xiu xia, Sun Lin yan, "The impact analysis of logistics ability to regional economics development," Science \& technology progress and policy, Vol. 10, 2006, pp. 30-33.

[10] LIU Bing-lian, YU Yong-ze, "An Empirical Analysis on the Regional Disparity of Efficiency and Factor in China`s Logistics-Based on DEA and Tobit Model," China Business and Market, 2010, 09:18-21. 